Check for updates

Cite this: Sustainable Energy Fuels, 2017, 1, 2101

Received 23rd June 2017

Accepted 23rd September 2017

DOI: $10.1039 / c 7 s e 00304 h$

rsc.li/sustainable-energy

\section{Exploring effects of intermittent light upon visible light promoted water oxidations $\uparrow$}

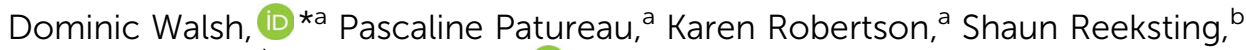 \\ Anneke Lubben, ${ }^{\mathrm{b}}$ Salvador Eslava (iD ${ }^{\mathrm{c}}$ and Mark T. Weller ${ }^{\mathrm{a}}$
}

\begin{abstract}
Visible light promoted photocatalytic water oxidations for potential solar fuel production have been studied widely, with many reports on optimization of reagent components. Here we report an exploration on the effects upon ongoing reactions of daylight equivalent light intensity illumination with regulated short dark periods of a few seconds duration as compared to standard continuous illumination. Comparison was made with systems employing synthesized low cost earth abundant iron oxide, calciumoxomanganite and cobalt oxide nanoparticulate catalysts together with a $\left[\mathrm{Ru}(\mathrm{bpy})_{3}\right]^{2+}$ light harvesting dye and an electron acceptor. Yields of gaseous $\mathrm{O}_{2}$ and proton production were measured in situ and in real time. The study found that low cost catalysts could give very significantly increased $\mathrm{O}_{2}$ yields, turn over frequency and improved reaction profiles by use of simple on/off illumination. A range of timings with identical overall photon flux were tested and an optimum determined. Analysis of effects upon the light sensitizer under the range of lighting conditions (through mass spectrometry and UV-vis measurements), together with implementation of a continuous flow system as comparison to the batch reactions, were all employed to help elucidate the mechanisms for the clear improvements in reaction yields observed. These are believed to stem from reduction in self-decomposition of excess oxidized sensitizer and better synchronization of cyclic sensitizer oxidation/reductions with water oxidation at the metal oxide surface at specific light on : off timing.
\end{abstract}

\section{Introduction}

In tandem with solar photovoltaics, the capture and storage of energy in the form of convenient, inexpensive liquid fuels is an essential goal but remains technically challenging. The design of solar-fuel generation systems with the required efficiency, scalability, and sustainability to be economically viable has clear benefits. Artificial photosynthesis utilizing processes that are akin to photosystem II (PSII) water oxidation linked with development of photosystem I (PSI)-like systems with the necessary adaptions for solely liquid fuel production is a vital technological aim for generation of liquid solar fuels. ${ }^{1-3}$

Water oxidation typically utilizes the photocycling light absorbing dye $\left[\mathrm{Ru}(\mathrm{bpy})_{3}\right]^{2+}$. The metal-to-ligand charge-transfer (MLCT) visible absorption region of the $\left[\mathrm{Ru}(\mathrm{bpy})_{3}\right]^{2+}$ light

\footnotetext{
${ }^{a}$ Department of Chemistry, University of Bath, Bath, BA2 7AY, UK. E-mail: d.walsh2@ bath.ac.uk

${ }^{b}$ Chemical Characterization and Analysis Facility, University of Bath, Bath, BA2 7AY, $U K$

${ }^{c}$ Department of Chemical Engineering, University of Bath, BA2 7AY, UK

$\dagger$ Electronic supplementary information (ESI) available: Powder XRD of metal oxides, full experimental and equipment details, quantitative EDX of mild acid treated $\mathrm{CaMn}_{3} \mathrm{O}_{6}$, full scale MS spectroscopy of reaction mixtures and deposits, flow system experimental details, example calculations. See DOI: 10.1039/c7se00304h
}

sensitizer is at $\sim 410-510 \mathrm{~nm}\left(\lambda_{\max } 454 \mathrm{~nm}\right)$ (Fig. 1 inset). Hence for this light dependant component of the cyclic reaction, shorter wavelength visible light is effective in promotion of ruthenium d orbital electrons onto orbitals associated with a bipyridine ligand to give an excited state $\mathrm{Ru}(\mathrm{bpy})_{3}{ }^{2+} *$ (with relatively long lifetime of $\sim 0.65 \mu \mathrm{S}$ in $\mathrm{N}_{2}$ degassed aqueous solution $).{ }^{4}$ An electron acceptor $\left(\left(\mathrm{Co}\left(\mathrm{NH}_{3}\right)_{5} \mathrm{Cl}\right) \mathrm{Cl}_{2}\right)$ quenches the excited state $\left[\mathrm{Ru}(\mathrm{bpy})_{3}\right]^{2+*}$, giving $\left[\mathrm{Ru}(\mathrm{bpy})_{3}\right]^{3+}{ }^{5}$ Somewhat akin to natural photosynthesis, light independent steps then occur in which an electron donated from a metal oxide catalyst restores the stable $\left[\mathrm{Ru}(\mathrm{bpy})_{3}\right]^{2+}$ state, and absorbed water is subsequently oxidized on the metal oxide surface with the release of $\mathrm{O}_{2}$ and protons. This catalysed oxidation is reported to be the rate limiting step for final generation of gaseous oxygen. ${ }^{6,7}$ In total, four photons generate four protons and one $\mathrm{O}_{2}$ molecule..$^{, 8,9}$

$2 \mathrm{H}_{2} \mathrm{O}+4 h \nu \rightarrow \mathrm{O}_{2} \uparrow+4 \mathrm{H}^{+}$(to buffer) $+4 \mathrm{e}^{-}$(to $\mathrm{Ru}^{3+} / \mathrm{e}^{-}$acceptor)

Previously, we have investigated the effect of catalyst composition and a range of daylight equivalent light intensities at constant levels over a reaction lifetime. ${ }^{10}$ Recently we reported an observation that indicated constant illumination of fluctuating intensity could alter yields and turn over frequency (TOF) significantly. ${ }^{\mathbf{1 1}}$ In this article we have significantly 

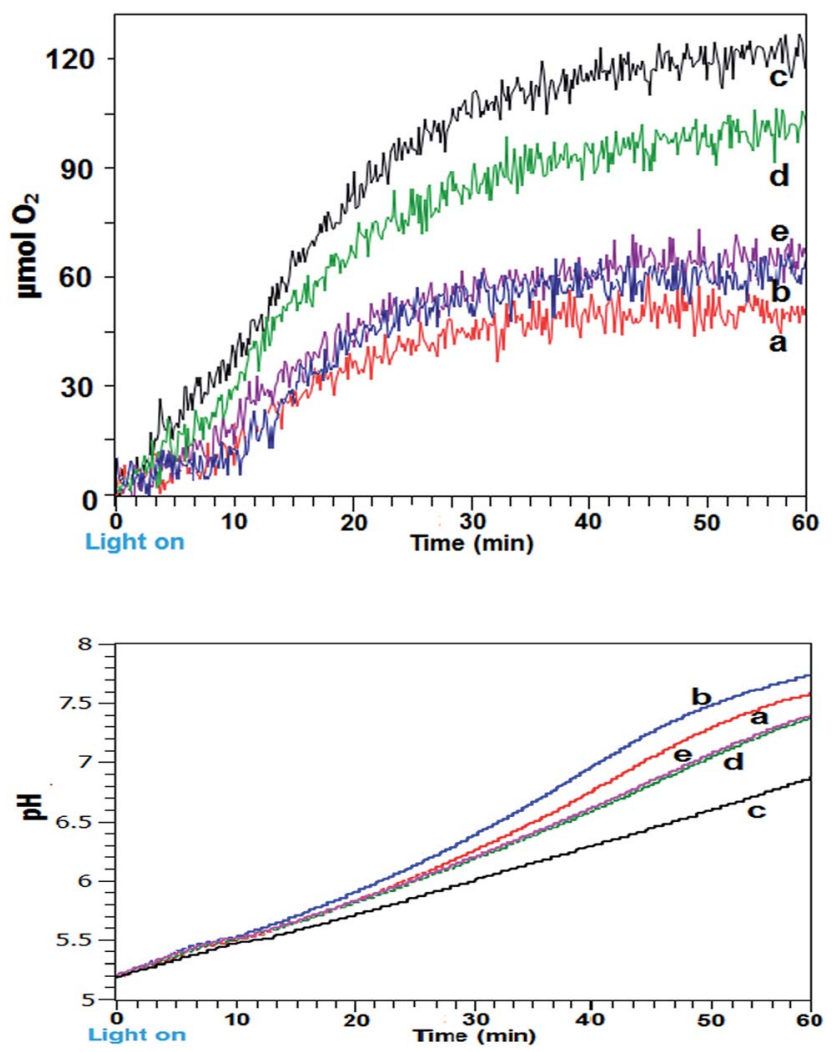

Fig. 1 (a) Graph of released $\mathrm{O}_{2}(\mu \mathrm{mol})$ against time for photocatalyzed water oxidation using a $\alpha / \gamma-\mathrm{Fe}_{2} \mathrm{O}_{3}$ catalyst, $\mathrm{Ru}(\mathrm{bpy})_{3}{ }^{2+}$ light harvester and $\left[\mathrm{Co}\left(\mathrm{NH}_{3}\right)_{5} \mathrm{Cl}\right] \mathrm{Cl}_{2}$ electron acceptor reaction mixture employing a blue LED ( $\lambda_{\max } 448 \mathrm{~nm}$ ) a $5 \mathrm{~mW} \mathrm{~cm}^{-2}$ light source of continuous or repeated light on: off cycles (s: s) of (a) continuous; (b) $12: 1$; (c) $24: 2$; (d) $36: 3$; (e) $48: 4$. (b) Graph of $\mathrm{pH}$ change of for $\mathrm{Fe}_{2} \mathrm{O}_{3}$ systems using repeated light on : off cycles (s: s) of (a) continuous; (b) $12: 1$; (c) $24: 2$; (d) $36: 3$; (e) $48: 4$.

developed on this underexplored theme. A range of earth abundant and low cost metal oxide catalysts were compared, including a commercial nanoparticulate $\mathrm{Co}_{3} \mathrm{O}_{4}$ as a known high performing catalyst. ${ }^{12}$ The system employed a LED light source controlled with a high accuracy electronic on/off timer. Initially a wide range of timings were used to locate an optimal zone for improved activity, further refinements then pinpointed the optimal timing for maximum efficiency.

Mass spectrometry (MS) and UV-vis spectroscopy analysis were used to determine relative levels of light sensitizer decomposition and to elucidate mechanisms for the improved efficiencies. In comparison to reactions under constant illumination, an approximate doubling of gaseous $\mathrm{O}_{2}$, proton yield and measured TOF was obtained when optimized timing was used for reactions that were otherwise identical.

\section{Experimental}

\section{Preparation of metal oxide catalysts}

Nanoparticulate iron oxide $\left(\alpha-\mathrm{Fe}_{2} \mathrm{O}_{3}\right.$-hematite $/ \gamma-\mathrm{Fe}_{2} \mathrm{O}_{3}$ maghemite $)$ and calcium oxomanganite $\left(\mathrm{CaMn}_{3} \mathrm{O}_{6}\right)$ were prepared as previously reported. ${ }^{11,13}$ Details of the synthesis are given in the ESI. $\dagger$
Comparison also included use of a commercial nanoparticulate $\mathrm{Co}_{3} \mathrm{O}_{4}$ (Sigma-Aldrich 637025, measured $S_{\mathrm{BET}}=35.8 \mathrm{~m}^{2} \mathrm{~g}^{-1}$ ).

\section{Characterization}

Powder X-ray diffraction. Powder samples were analysed using a Bruker D8 powder X-ray diffractometer $(\mathrm{CuK} \alpha)$ with a PSD LynxEye Detector. Metal oxides employed were confirmed as $\alpha / \gamma-\mathrm{Fe}_{2} \mathrm{O}_{3}$ (hematite, JCPDS 013-0534) with a trace level of maghemite, (JCPDS 024-081), calcium oxomanganite $\mathrm{CaMn}_{3} \mathrm{O}_{6}$ (ref. 14) and cobalt oxide $\left(\mathrm{Co}_{3} \mathrm{O}_{4}\right.$, JCPDS 00-042-1467) (see Fig. S1a-c ESI†).

Surface area analysis (BET). Calculated Brunauer-EmmettTeller (BET) specific surface areas from gas sorption $\left(\mathrm{N}_{2}, 77 \mathrm{~K}\right)$ were measured on Micromeritics 3-Flex gas sorption analyser. Before the analysis, the sample was pre-degassed at $150{ }^{\circ} \mathrm{C}$ for 8 hours under vacuum $\left(10^{-3} \mathrm{mbar}\right)$ in an oven and then degassed at $200^{\circ} \mathrm{C}$ for 12 hours under dynamic high vacuum $\left(10^{-6} \mathrm{mbar}\right)$. BET $\mathrm{N}_{2}$ adsorption surface area measurements gave surface areas of $36.3 \mathrm{~m}^{2} \mathrm{~g}^{-1}, 4.72 \mathrm{~m}^{2} \mathrm{~g}^{-1}$ and $61.3 \mathrm{~m}^{2} \mathrm{~g}^{-1}$ for the $\mathrm{Fe}_{2} \mathrm{O}_{3}$, $\mathrm{CaMn}_{3} \mathrm{O}_{6}$ and $\mathrm{Co}_{3} \mathrm{O}_{4}$ samples respectively.

Emission spectra. Visible light emission spectra from the LED light source was measured using a Perkin-Elmer LS55 Luminescence Spectrometer in phosphorescence emission mode with the LED light directed via an optical fibre used in place of the spectrometer light source. WinLab Version 4.00.03 software via a linked PC was used for collecting data.

FIA-QTOF mass spectrometry analysis. The flow injection analyses (FIA) were conducted using a MaXis HD electrospray ionization quadrupole time-of-flight (ESI-QTOF) mass spectrometer (Bruker Daltonik GmbH, Bremen, Germany) which was coupled to an Ultimate 3000 UHPLC (Thermo Fisher Scientific, California, USA). Analyses were performed using ESI positive-ion mode. The capillary voltage was set to $4500 \mathrm{~V}$, nebulizing gas at $4 \mathrm{bar}$, drying gas at $12 \mathrm{~L} \mathrm{~min}^{-1}$ at $220^{\circ} \mathrm{C}$. The time of flight scan range was from 50-750 mass-to-charge ratio $(\mathrm{m} / \mathrm{z})$. Mobile phases A and B comprised MS-grade water (Merck) and methanol (Merck), respectively. Flow injections were set up to introduce $10 \mu \mathrm{L}$ of sample with $50 \%$ B mobile phase at a flow rate of $0.05 \mathrm{ml} \mathrm{min}^{-1}$. The MS instrument was calibrated using a range of sodium formate clusters similarly introduced during FIA by $10 \mu \mathrm{L}$ loop-injection. The mass calibrant solution consisted of 3 parts of $1 \mathrm{M} \mathrm{NaOH}$ to 97 parts of $50: 50$ water : isopropanol with $2 \%$ formic acid. The observed mass and isotope pattern matched the corresponding theoretical values as calculated from the expected elemental formula within $2 \mathrm{ppm}$ mass accuracy. Data processing was performed using the Compass Data Analysis software version 4.3 (Bruker Daltonik GmbH, Bremen, Germany).

UV-visible absorption. Samples in methanol were placed into a quartz cuvette before being examined by a Perkin Elmer UV/VIS/NIR Lambda 750S spectrophotometer at absorption wavelengths between $350-700 \mathrm{~nm}$ and a speed of $240 \mathrm{~nm}$ per minute. The reference used was methanol.

Visible light promoted water oxidations. Full details of the experimental conditions and equipment are described in the ESI. $\dagger$ Briefly, a $50 \mathrm{ml}$ glass flask was taken and $125 \mathrm{mg}(0.01426 \mathrm{~mol})$ of 
$\left[\mathrm{Co}\left(\mathrm{NH}_{3}\right)_{5} \mathrm{Cl}\right] \mathrm{Cl}_{2}(98 \%)$ electron acceptor and $45 \mathrm{mg}(1.717 \times$ $\left.10^{-3} \mathrm{~mol}\right)\left[\mathrm{Ru}(\mathrm{bpy})_{3}\right] \mathrm{Cl}_{2} \cdot 6 \mathrm{H}_{2} \mathrm{O}(99.95 \%)$ sensitizer were added together with $20 \mathrm{ml}$ of $\mathrm{N}_{2}$ degassed $50 \mathrm{mM}$ acetate buffer (pH 5.2). The reaction flask was covered with foil to shield from light and stirred for 5 minutes to allow the electron acceptor to fully dissolve. $10 \mathrm{mg}$ of the metal oxide catalyst suspended in a further $15 \mathrm{ml}$ of degassed buffer was then added to the reaction flask. The light shielded flask was then left stirring for 20 minutes for the system to equilibrate.

A 3 W LED was utilized as light source, placed at distance from the side of the flask such that a measured emission of 5 $\mathrm{mW} \mathrm{cm}{ }^{-2}$ intensity of blue light $\left(\lambda_{\max } 448 \mathrm{~nm}\right)$ reached the outer flask surface adjacent to the stirred reaction mixture. A constant DC voltage/amp supply coupled with a timer module (accurate to $\pm 0.005 \mathrm{~s}$ ) was used to control LED illumination on : off periods. In situ real-time measurement of gaseous $\mathrm{O}_{2}$ released into the flask headspace was conducted using an accurate optical sensor system. Increase in $\mathrm{O}_{2} \mathrm{ppm}$ into the known headspace volume was used to calculate $\mu \mathrm{molO}_{2}$ generated. A $\mathrm{pH}$ probe placed within the stirred reaction mixture recorded pH change. ${ }^{\mathbf{1 0 , 1 5}}$ Efforts were made to ensure high consistency between reaction measurements, which were made in triplicate. Yield and profiles for repeat experiments were consistent and representative profiles shown. Collection of samples and dilutions in methanol for MS analysis are detailed in the ESI Experimental section. $\dagger$

Flow system for photocatalytic water oxidations. Full details of the experimental set-up are given in the ESI. $\dagger$ A stirred $350 \mathrm{ml}$ reservoir of prepared $\mathrm{N}_{2}$ degassed $50 \mathrm{mM}$ acetate buffer containing $\left[\mathrm{Co}\left(\mathrm{NH}_{3}\right)_{5} \mathrm{Cl}\right] \mathrm{Cl}_{2},\left[\mathrm{Ru}(\mathrm{bpy})_{3}\right] \mathrm{Cl}_{2} \cdot 6 \mathrm{H}_{2} \mathrm{O}$ and $\mathrm{Co}_{3} \mathrm{O}_{4}$ catalyst were used, at equivalent proportion to the $35 \mathrm{ml}$ bulk reaction mixture. The reaction mixture was passed through the $1.5 \mathrm{~mm}$, ID flow reactor in discrete $0.022 \mathrm{~cm}^{3}$ segments (separated by air segments). A $60 \mathrm{~cm}$ section of coiled tubing was illuminated by

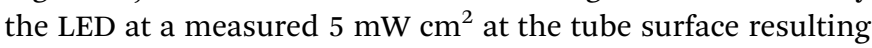
in $1 \mathrm{~min} 58 \mathrm{~s}$ reaction time (net flow rate $750 \mu \mathrm{l}$ ) when illuminated constantly. $\mathrm{pH}$ and $\mathrm{O}_{2}$ concentration were measured continuously, since the reaction volume was only $0.022 \mathrm{~cm}^{3}$, fluctuations in $\mathrm{O}_{2}$ levels could only give an indication of changes. Cycles of $30 \mathrm{~min}$ illumination and $10 \mathrm{~min}$ dark were employed to ascertain the time to steady state of the photowater oxidation.

\section{Results and discussion}

\section{Intermittent light reactions with $\mathrm{Fe}_{2} \mathrm{O}_{3}$ as catalyst}

Initial experiments employed a simple $\alpha / \gamma-\mathrm{Fe}_{2} \mathrm{O}_{3}$ as catalyst in the reaction mixture to locate the optimal zone and period of on : off (both in seconds) illumination in comparison to constant illumination. Fig. 1a shows gaseous $\mathrm{O}_{2}$ generation and yield profiles for differing lighting conditions for $60 \mathrm{~min}$ photoreactions. Use of intermittent light at $4: 1$ and $6: 1$ on : off ( $\mathrm{s}: \mathrm{s}$ ) was detrimental for reaction rates (not shown), at $12: 1(\mathrm{~s}: \mathrm{s})$ the initial reaction rate matched that of the continuous system before overtaking after $\sim 16 \mathrm{~min}$ and overall only very marginal improvement was obtained, presumably because light influx was interrupted too frequently at these on : off illumination settings. Conversely at $48: 4$ (s:s), the dark periods were apparently overlong. In both these instances the timings were far from optimally tuned for improvements to the reaction mechanism. It should be noted that the intermittent light timings shown had fixed on : off ratios and thus identical overall photon flux.

Significantly, at $36: 3$ and $24: 2$ on : off (s:s) timings cycled for the $60 \mathrm{~min}$ reaction duration the measured profiles clearly showed a marked increase in initial rate together with a prolongation of reaction lifetime. This was reflected in increased $\mathrm{O}_{2}$ yield and TOF over the first $30 \mathrm{~min}$. At $24: 2$ (s : s) timing a yield of $120 \mu \mathrm{mol} \mathrm{O}_{2}$ and TOF of $5.57 \times 10^{-4} \mathrm{~s}^{-1}$ was obtained, the oxygen yield was close the theoretical maximum of $125 \mu \mathrm{mol}$ based on electron acceptor concentration. Also, for the optimal timings, the reaction profiles continued to show a slight upward incline at longer time as opposed to the leveling off shown with the other systems.

From the light dependant sensitizer redox cycling, decomposition of the $\left[\mathrm{Co}\left(\mathrm{NH}_{3}\right)_{5} \mathrm{Cl}\right] \mathrm{Cl}_{2}$ electron acceptor with evolution of ammonia results in $\mathrm{pH}$ rise for the photocatalytic system. Corresponding $\mathrm{pH}$ measurements for the reactions are shown in Fig. 1b. A trend of more rapidly increasing and higher final $\mathrm{pH}$ was shown for the less efficient reactions. Highest $\mathrm{pH}$ was obtained with intermittent light at $12: 1$ (s:s) followed by the continuously lit system. Systems using $36: 3$ (s:s) and $48: 4$ ( $\mathrm{s}: \mathrm{s}$ ) gave near identical $\mathrm{pH}$ profiles however the best performing $24: 2$ (s : s) showed a smoother upward $\mathrm{pH}$ trend with lower final $\mathrm{pH}$ of 6.75 . With a more optimized water oxidation process the proton production may have led to reduced $\mathrm{pH}$ rise for this system. It is known that the oxidised sensitizer (i.e. $\left.\left[\mathrm{Ru}(\mathrm{bpy})_{3}\right]^{3+}\right)$ is unstable and prone to hydroxyl attack on the bipyridine rings at $\mathrm{pH}>7$ which contributed to shutdown of the reaction at higher $\mathrm{pH}^{16,17}$

\section{Intermittent light reactions with $\mathrm{CaMn}_{3} \mathrm{O}_{6}$ as catalyst}

The photocatalytic reactions were repeated using a synthesized $\mathrm{CaMn}_{3} \mathrm{O}_{6}$ catalyst as a basic analogue of the PSII Oxygen Evolving Centre (OEC) $\mathrm{CaMn}_{4} \mathrm{O}_{5}$ cluster. ${ }^{18,19}$ In previous work we have identified that a crystalline calcium oxomanganite with formula of $\mathrm{CaMn}_{3} \mathrm{O}_{6}$ was the most efficient under the reaction conditions used. ${ }^{20}$ Experiments were conducted using continuous illumination and using a range of timings around the optimal $24: 2$ (s : s) identified with the iron oxide system. A graph of $\mathrm{O}_{2}$ yields against time and corresponding $\mathrm{pH}$ measurements using these conditions is shown in Fig. 2a and b. Firstly, the results indicate that the optimal zone for improved reaction rate was quite narrow and within $0.5 \mathrm{~s}$. Using 24 : 1.5 ( $\mathrm{s}: \mathrm{s}$ ) gave little improvement compared to continuous illumination. Longer dark periods of $2.5 \mathrm{~s}$ produced a more marked improvement but a clearer increased yield was obtained at $24: 2$ (s : s) timing, producing $120 \mu \mathrm{mol} \mathrm{O}_{2}$ and having a TOF of $7.34 \times 10^{-4} \mathrm{~s}^{-1}$.

For this system the best performing $24: 2$ (s : s) illumination system gave highest final $\mathrm{pH}$ in contrast to the $\alpha / \gamma-\mathrm{Fe}_{2} \mathrm{O}_{3}$ catalysed system. Quantitative EDX analysis of the $\mathrm{CaMn}_{3} \mathrm{O}_{6}$ catalyst after stirring in $\mathrm{pH} 5.5$ acetate buffer for $10 \mathrm{~min}$ showed 

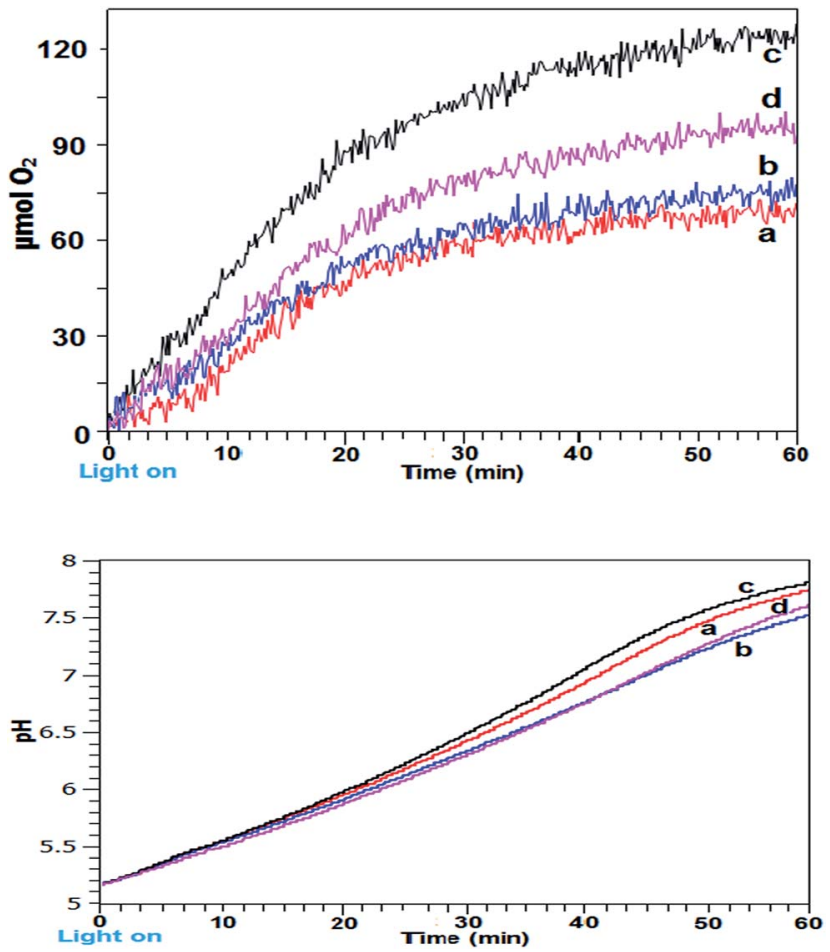

Fig. 2 (a) Graph of released $\mathrm{O}_{2}$ ( $\mu \mathrm{mol}$ ) against time for a photocatalytic system using $\mathrm{CaMn}_{3} \mathrm{O}_{6}$ as catalyst and light using repeated light on : off cycles (s: s) of (a) continuous; (b) $24: 1.5$; (c) 24 : 2; (d) 24 : 2.5. (b) Graph of $\mathrm{pH}$ change for $\mathrm{CaMn}_{3} \mathrm{O}_{6}$ reaction systems using repeated light on : off cycles (s: s) of (a) continuous; (b) $24: 1.5$; (c) $24: 2$; (d) $24: 2.5$

a reduction in relative calcium levels with measured at $\%$ Mn : Ca 3.1:1 changing to 3.9:1 due to preferential $\mathrm{Ca}$ dissolution from the catalyst (Fig. S2 and Table S1 ESI $\dagger$ ). Thus, the difference in final $\mathrm{pH}$ of the photoreaction can be ascribed to some protons being diverted to attack on the calcium component of $\mathrm{CaMn}_{3} \mathrm{O}_{6}$ crystals.

\section{Intermittent light reactions with $\mathrm{Co}_{3} \mathrm{O}_{4}$ as catalyst}

As a final evaluation, the reactions were conducted employing a commercial nanoparticulate $\mathrm{Co}_{3} \mathrm{O}_{4}$ using continuous and the optimal $24: 2$ (s : s) timing identified (Fig. 3a and b). Under the reaction conditions used with continuous light the catalyst performed relatively well compared to the other systems. Using 24-2 timing an improvement was still evident however, though to a lesser degree. $\mathrm{pH}$ profiles were near identical, suggesting that with intermittent light the $\mathrm{Co}_{3} \mathrm{O}_{4}$ proton production process contributed to suppressing $\mathrm{pH}$ rise.

Reaction conditions, $\mu$ mol $\mathrm{O}_{2}$ and calculated TOFs and quantum yields $(\phi)$ for the measurement for the three catalysts are shown in Table 1 . The $\alpha / \gamma-\mathrm{Fe}_{2} \mathrm{O}_{3}$ catalyst demonstrated the most marked increase in TOF under optimal (24:2 (s:s)) intermittent lighting showing with a 2.31 times increase, $\mathrm{CaMn}_{3} \mathrm{O}_{6}$ catalysis gave 1.91 and $\mathrm{Co}_{3} \mathrm{O}_{4}$ a 1.51 times increase. The TOF improvement was thus a function of intrinsic catalysis effectiveness with the scope lessening for more active catalysts.

Since the $\mathrm{CaMn}_{3} \mathrm{O}_{6}$ catalyst has been shown to be subject to compositional change during the photo-reaction, the use of active
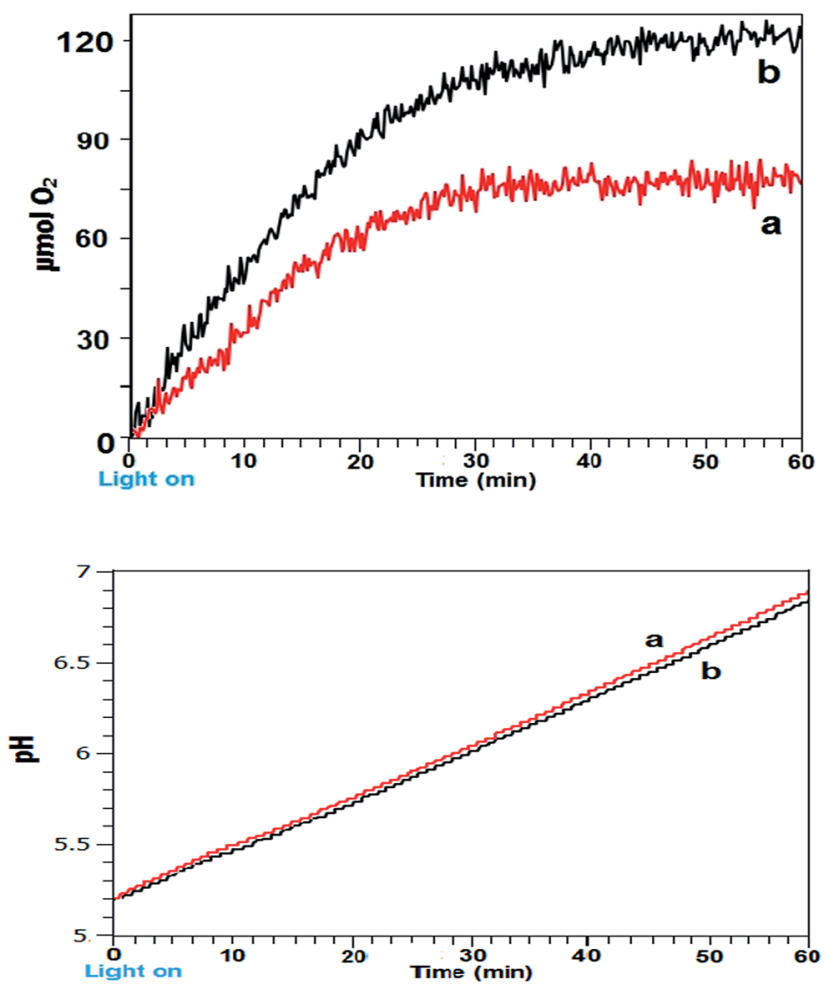

Fig. 3 (a) Graph of released $\mathrm{O}_{2}$ ( $\mu \mathrm{mol}$ ) against time for a photocatalytic system using $\mathrm{CO}_{3} \mathrm{O}_{4}$ as catalyst and light using repeated light on : off cycles (s: s) of (a) continuous; (b) 24 : 2. (b) Graph of pH change for $\mathrm{CO}_{3} \mathrm{O}_{4}$ reaction systems using repeated light on : off cycles (s: s) of (a) continuous; (b) $24: 2$.

site area for rate calculations may be misleading, a photonic method was thus employed. Previous work indicated that levels of in situ generated cobalt oxides and hydroxides from electron acceptor decomposition that can contribute to $\mathrm{O}_{2}$ generation becomes significant after approximately $40 \mathrm{~min} .{ }^{15}$ Therefore total $\mathrm{O}_{2}$ yields at 40 min was used for yield and $\phi$ calculations.

\section{Mass spectrometry analysis}

To help elucidate the mechanism for the significantly improved reaction efficiencies observed in these systems, mass spectrometry analysis was conducted on the post reaction $\mathrm{CaMn}_{3} \mathrm{O}_{6}$ and $\mathrm{Fe}_{2} \mathrm{O}_{3}$ mixtures formed using continuous and intermittent lighting. Methanol was used as the MS carrier solvent, thus allowing more distinct analysis of the highly soluble $\left[\mathrm{Ru}(\mathrm{bpy})_{3}\right]^{2+}$ component. A brown coloured deposit also gradually formed on the illuminated flask surface. In this photoaquation process bipyridine ligands are displaced from the ruthenium and can be observed to accumulate in the form of a low water solubility hydrocarbon rich coating. ${ }^{11,17,21}$ This was also quantitatively collected and analysed by MS to provide an assessment of the entire reaction timescale.

\section{Mass spectrometry of $\mathrm{CaMn}_{3} \mathrm{O}_{6}$ reaction mixtures}

MS analysis of the reaction mixture prior to illumination is shown in Fig. S3a ESI, $\uparrow$ a large $\left[\mathrm{Ru}(\mathrm{bpy})_{3}\right]^{2+} z=2$ peak at $\mathrm{m} / \mathrm{z}$ 
Table 1 Maximum net $\mathrm{O}_{2}$ generated, calculated TOFs (TOF as mol $\mathrm{O}_{2}$ per s per mol (active) metal). Quantum yield $\phi \mathrm{O}_{2} \%=\mathrm{O}_{2}$ produced at $t=$ $\mathrm{O}_{2}$ max@40 min per photons absorbed at $t=40 \mathrm{~min} \times 400 \%$ ( 4 photons absorbed per $\mathrm{O}_{2}$ ). $\mathrm{S}_{\mathrm{BET}}, \mathrm{m}^{2} \mathrm{~g}^{-1} \alpha / \gamma-\mathrm{Fe}_{2} \mathrm{O}_{3}=36.3, \mathrm{CaMn}_{3} \mathrm{O}_{6} 4.72, \mathrm{Co}_{3} \mathrm{O}_{4}$ $=35.8$. Light source $=$ blue LED $\left(\lambda_{\max } 448 \mathrm{~nm}\right)$, linked to on/off timer unit, intensity of $5 \mathrm{~mW} \mathrm{~cm}^{-2}$ at flask surface (example calculations are shown in the ESI†)

\begin{tabular}{|c|c|c|c|c|}
\hline Catalyst (10 mg) & $\begin{array}{l}\text { Light conditions } \\
\text { cyclic on : off }(\mathrm{s}: \mathrm{s})\end{array}$ & $\begin{array}{l}\mathrm{O}_{2} \text { yield } \\
\text { (at } t=40 \mathrm{~min}) \mu \mathrm{mol}\end{array}$ & $\begin{array}{l}\mathrm{TOF}_{\max } \\
(t=0-20 \mathrm{~min}) 10^{-4} \mathrm{~s}^{-1}\end{array}$ & $\begin{array}{l}\phi \mathrm{O}_{2} \% \text { at } \\
t=40 \mathrm{~min}\end{array}$ \\
\hline$\alpha / \gamma-\mathrm{Fe}_{2} \mathrm{O}_{3}$ & Continuous & 52 & 2.41 & 14.4 \\
\hline$\alpha / \gamma-\mathrm{Fe}_{2} \mathrm{O}_{3}$ & $24: 2$ & 116 & 5.57 & 35 \\
\hline$\alpha / \gamma-\mathrm{Fe}_{2} \mathrm{O}_{3}$ & $36: 3$ & 96 & 4.36 & 29.1 \\
\hline$\alpha / \gamma-\mathrm{Fe}_{2} \mathrm{O}_{3}$ & $48: 4$ & 61 & 2.93 & 18.5 \\
\hline $\mathrm{CaMn}_{3} \mathrm{O}_{6}$ & $24: 2$ & 117 & 7.34 & 35.3 \\
\hline $\mathrm{CaMn}_{3} \mathrm{O}_{6}$ & $24: 2.5$ & 86 & 5.25 & 26.6 \\
\hline $\mathrm{Co}_{3} \mathrm{O}_{4}$ & Continuous & 80 & 4.1 & 22.3 \\
\hline $\mathrm{Co}_{3} \mathrm{O}_{4}$ & $24: 2$ & 119 & 6.2 & 35.9 \\
\hline
\end{tabular}

285.05 with surrounding $\mathrm{Ru}$ isotope peaks was measured. Photocatalytic reactions resulted in emergence of multiple peaks ranging from 96 up to $610 \mathrm{~m} / \mathrm{z}$, full scale spectrograms are shown in Fig. S3b-e ESI. $\dagger$ Key features of the spectrometry can be seen associated around the intact $\left[\mathrm{Ru}(\mathrm{bpy})_{3}\right]^{2+}$. Fig. S4 ESI $\dagger$ shows a Ru isotope separation of $0.5 \mathrm{Da}$ further confirming the $2^{+}$ion charge. The adjacent decomposition product at $\mathrm{m} / \mathrm{z}$ 282.279 , was a saturated hydrocarbon of composition $\mathrm{C}_{18} \mathrm{H}_{35} \mathrm{NO}$ $\left(\mathrm{H}^{+}\right)$without $\mathrm{Ru}$ present, as indicated by isotope mass analysis (Fig. 4a-d).

Notably $\left[\mathrm{Ru}(\mathrm{bpy})_{3}\right]^{2+}: \mathrm{C}_{18} \mathrm{H}_{35} \mathrm{NO}$ peaks are either equivalent or decomposition product rich with the poorer performing continuous and $24: 1.5$ (s:s) timing system. The converse situation was obtained at $24: 2(\mathrm{~s}: \mathrm{s})$ and $24: 2.5(\mathrm{~s}: \mathrm{s})$ timing

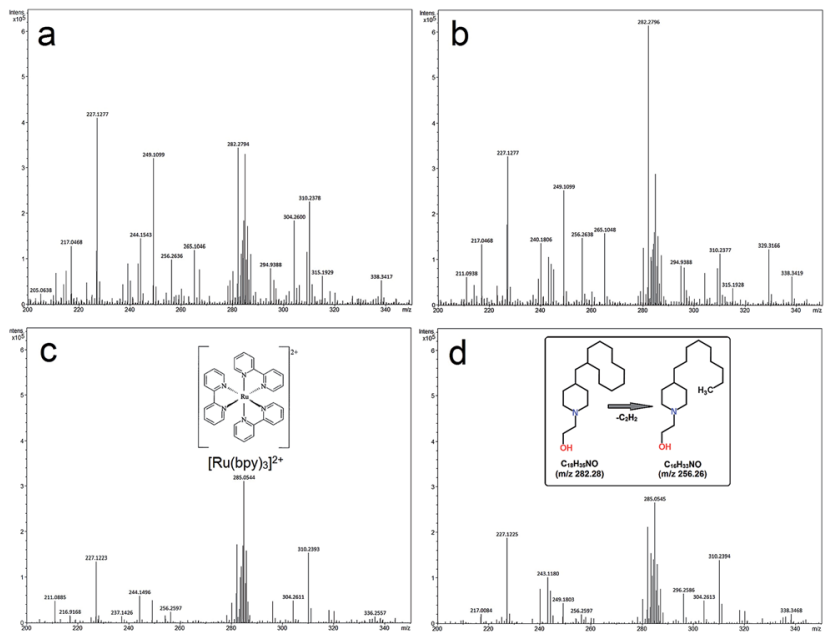

Fig. 4 Mass spectrometry analysis of post 60 min photocatalytic reaction mixtures using $\mathrm{CaMn}_{3} \mathrm{O}_{6}$ catalyst, $\left[\mathrm{Ru}(\mathrm{bpy})_{3}\right]^{2+}$ and $\left[\mathrm{Co}\left(\mathrm{NH}_{3}\right)_{5} \mathrm{Cl}\right] \mathrm{Cl}_{2}$ reaction mixture with light source of continuous illumination or intermittent on : off (s: s) of (a) continuous; (b) $24: 1.5$; (c) $24: 2$; (d) $24: 2.5$. Intact $m / z\left[R u(b p y)_{3}\right]^{2+}(z=2)$ peak at 285.054 was evident in all reactions mixtures together with multiple decomposition product peaks, notably at $\mathrm{m} / \mathrm{z} 282.279,256.263,249.109$ and 227.12. Inset shows possible structure of the major decomposition product and an associated fragment. with highest intact $\left[\mathrm{Ru}(\mathrm{bpy})_{3}\right]^{2+}$ present in the best performing $24: 2$ (s : s) system (Fig. 4c).

\section{Mass spectrometry of $\mathrm{CaMn}_{3} \mathrm{O}_{6}$ reaction flask deposits}

An example image of the rinsed post-reaction flask and filtered deposits collected in methanol are shown in Fig. 5a-c. Mass spectrometry analysis of the lower water-soluble deposits collected from the flask surface were rich in hydrocarbon deposits formed from degradation of reagents. MS results from analysis of deposits from the $\mathrm{CaMn}_{3} \mathrm{O}_{6}$ catalysed system with continuous light and $24: 2$ (s : s) timing are shown in Fig. 5d and e. Results show a greater relative level of decomposed material present when continuous illumination was employed
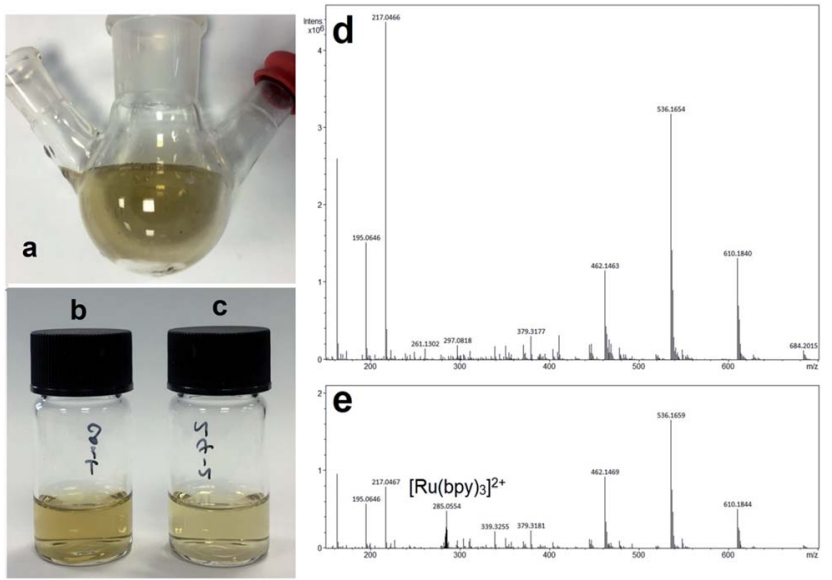

Fig. 5 Images showing (a) reaction flask with accumulated surface coating after continuous illumination of photocatalytic reaction with $\mathrm{CaMn}_{3} \mathrm{O}_{6}$ catalyst, $\left[\mathrm{Ru}(\mathrm{bpy})_{3}\right]^{2+}$ and $\left[\mathrm{Co}\left(\mathrm{NH}_{3}\right)_{5} \mathrm{Cl}\right] \mathrm{Cl}_{2}$. Filtered solution of flask deposit collected in methanol from reactions using (b) continuous illumination; (c) $24: 2$ (s: s) on : off. Mass spectra of the deposits corresponding to continuous and $24: 2$ (s:s) lighting are shown in (d) and (e). Peaks due to multiple fragments of decomposition products are shown to be of higher intensity in continuous illuminated systems whereas the presence of intact $\left[R u(b p y)_{3}\right]^{2+}$ in the intermittently lit $24: 2$ (s: s) system is shown. 
with no $\left[\mathrm{Ru}(\mathrm{bpy})_{3}\right]^{2+}$ detectable. In contrast, intact sensitizer at $\mathrm{m} / \mathrm{z} 285.055$ was clearly present with $24: 2$ (s : s) timing. Other major decomposition product peaks were present at $\mathrm{m} / \mathrm{z}$ 610.184, 536.165, 462.146 and 217.046 which correspond to $\mathrm{C}_{35} \mathrm{H}_{20} \mathrm{~N}_{11} \mathrm{O}, \mathrm{C}_{39} \mathrm{H}_{22} \mathrm{NO}_{2}, \mathrm{C}_{29} \mathrm{H}_{16} \mathrm{~N}_{7}$ and $\mathrm{C}_{8} \mathrm{H}_{5} \mathrm{~N}_{6} \mathrm{O}_{2}$ by isotope mass analysis.

A similar trend of relatively elevated levels of hydrocarbon deposits using continuous light was obtained with the other catalysed reaction systems (Fig. S5 and S6 ESI $\dagger$ ).

Overall the coating that formed on flasks from the photocatalysis was noted to be slightly darker coloured for reactions conducted using continuous illumination. However, coating build-up on the flask was gradual and the blocking effect of incoming light was not significant on early stage crucial reaction rates. The collected MS data indicates that intermittent light at $24: 2(\mathrm{~s}: \mathrm{s})$ and $24: 2.5(\mathrm{~s}: \mathrm{s})$ timings resulted in less decomposition of the $\left[\mathrm{Ru}(\mathrm{bpy})_{3}\right]^{2+}$ sensitizer, thus promoting a more efficient reaction. The MS data also suggest that the selfdecomposition of the oxidised unstable $\left[\mathrm{Ru}(\mathrm{bpy})_{3}\right]^{3+}$ to hydroxylated derivatives occurred via detachment of ruthenium combined with loss of the heterocyclic nitrogens.

Saturated hydrocarbons depleted in $\mathrm{N}$ were present at lower $\mathrm{m} / \mathrm{z}$, with some possible $\mathrm{N}$ rich compounds formed at high $\mathrm{m} / \mathrm{z}$, e.g. $\mathrm{C}_{35} \mathrm{H}_{20} \mathrm{~N}_{11} \mathrm{O}$ at $m / z 610.184$. The multi-peak isotope pattern for ruthenium is distinctive and no other fragments and decomposition products containing $\mathrm{Ru}$ were evident and it can be concluded that $\mathrm{Ru}$ oxides released from the decomposed $\left[\mathrm{Ru}(\mathrm{bpy})_{3}\right]^{2+}$ gradually formed insoluble aggregates along with some in situ generated cobalt oxides which were all removed by filtrations prior to MS analysis. ${ }^{15}$

\section{UV-visible spectroscopy analysis}

A UV-visible absorption spectrum for the $\left[\mathrm{Ru}(\mathrm{bpy})_{3}\right]^{2+} \mathrm{MLCT}$ band in methanol overlaid with the emission spectrum of the blue LED light source used in this study is shown in Fig. 6a.

The absorption spectra of carefully quantitatively gathered reaction mixtures after $60 \mathrm{~min}$ photocatalytic reaction using $\mathrm{Fe}_{2} \mathrm{O}_{3}$ or $\mathrm{CaMn}_{3} \mathrm{O}_{6}$ as the catalyst with continuous and intermittent light timings are shown in Fig. $6 \mathrm{~b}$ and c.

The absorption profiles are near identical in shape; however a greater absorption was obtained for systems that employed a timing of 24-2 (s : s). This agrees with the MS analysis which indicated more intact sensitizer was retained with intermittent lighting.

\section{Low reaction volume flow-system photocatalytic water oxidation}

Electron transitions, transfers and sensitizer excited state lifetime are on the order of micro/pico seconds, however it is reported that on illumination a sensitizer solution takes on the order of a few seconds for the major bulk of molecules to become oxidized. ${ }^{7}$

This timescale is due to circulation of reagent molecules around the illuminated surface. For the flask bulk reaction we have demonstrated that dark periods of a few seconds resulted in marked effects in reaction rates. This timescale can thus be
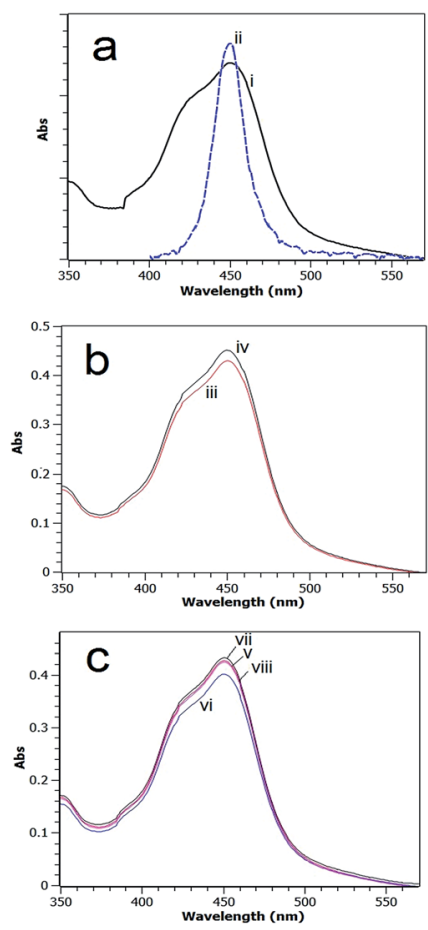

Fig. 6 UV-visible absorption spectra of (a) (i) $\left[\mathrm{Ru}(\mathrm{bpy})_{3}\right] \mathrm{Cl}_{2}$ in methanol $\left(\lambda_{\max } 450 \mathrm{~nm}\right)$ and (ii) LED light source emission $\left(\lambda_{\max } 448 \mathrm{~nm}\right)$; (b) reaction mixture after 60 min photocatalytic reaction with $\mathrm{Fe}_{2} \mathrm{O}_{3}$ catalyst, $\left[\mathrm{Ru}(\mathrm{bpy})_{3}\right]^{2+}$ and $\left[\mathrm{Co}\left(\mathrm{NH}_{3}\right)_{5} \mathrm{Cl}_{\mathrm{Cl}}\right.$ using illumination of (iii) continuous light; (iv) $24: 2$ (s:s) on: off. (c) Reaction mixture after 60 min photocatalytic reaction with $\mathrm{CaMn}_{3} \mathrm{O}_{6}$ catalyst, $\left[\mathrm{Ru}(\mathrm{bpy})_{3}\right]^{2+}$ and $\left[\mathrm{Co}\left(\mathrm{NH}_{3}\right)_{5} \mathrm{Cl}_{\mathrm{Cl}_{2}}\right.$ using illumination of (v) continuous; (vi) $24: 1.5$ (s : s); (vii) $24: 2$ (s : s); (viii) $24: 2.5$ (s: s). Highest sensitizer absorption was obtained for the systems that employed the $24: 2$ (s: s) timing.

ascribed to diffusion rates of reagent molecules in various oxidation states. To help elucidate the mechanism for improved reaction rate a segmented flow system using very low reaction mixture volumes was designed and tested. Here segments of $0.022 \mathrm{~cm}^{3}$ reaction solution were separated by air to prevent sedimentation of particles and back-mixing and generate mixing within each segment. Flow systems have been widely employed for photocatalytic degradation of water pollutants and for hydrogen production from photocatalyzed $\mathrm{TiO}_{2} / \mathrm{Pt}$ water flow systems. ${ }^{22,23}$

Used here, the flow system permits a continuous reaction under illumination. The reaction set-up employed is illustrated in Scheme 1 and Fig. S7, S8a and b ESI. $\dagger$ For this system, continuous lighting and a fast intermittent light $0.06: 0.005$ (s : s) on : off (ratio corrected from above batch method of $24: 2$ $(\mathrm{s}: \mathrm{s})$ ) were used and effects upon reaction mixture $\mathrm{pH}$ and indication of $\mathrm{O}_{2}$ yields measured. A graph of measured $\mathrm{pH}$ and relative gaseous $\mathrm{O}_{2}$ released by the continuous flowing reaction mixture under the differing lighting conditions is shown in Fig. 7aand b.

\section{Effects of intermittent illumination}

$\left[\mathrm{Ru}(\mathrm{bpy})_{3}\right]^{2+}$ has been extensively employed as the light harvester for photocatalytic water oxidations and is a costly 


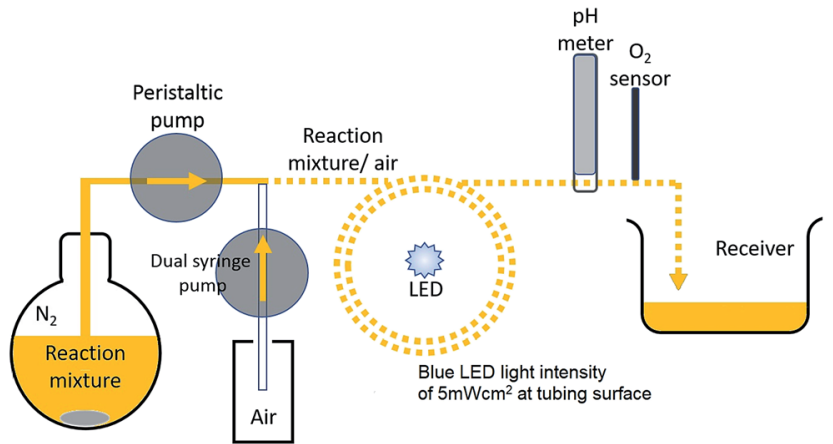

Scheme 1 Flow system set-up for continuous photo-catalysed water oxidations using $\left[\mathrm{Ru}(\mathrm{bpy})_{3}\right]^{2+},\left[\mathrm{Co}\left(\mathrm{NH}_{3}\right)_{5} \mathrm{Cl}_{\mathrm{Cl}}\right.$ and $\mathrm{CO}_{3} \mathrm{O}_{4}$ catalyst in $350 \mathrm{ml}$ of $\mathrm{N}_{2}$ degassed $50 \mathrm{mM}$ acetate buffer at $\mathrm{pH}$ 5.2. Illumination of $5 \mathrm{~mW} \mathrm{~cm}{ }^{2}$ at the surface of $60 \mathrm{~cm}$ of coiled section of tubing which contained $0.022 \mathrm{~cm}^{3}$ sections of reaction mixture separated by air gaps pumped at $750 \mu \mathrm{lmin} \mathrm{m}^{-1}$. $\mathrm{pH}$ and approximate elevation of $\mathrm{O}_{2}$ levels were recorded.

component of the reagent mixture. Improvements in reaction efficiency due to its reduced degradation has clear benefits for its use in sustainability applications.

Analysis by mass spectrometry showed intact $\left[\mathrm{Ru}(\mathrm{bpy})_{3}\right]^{2+}$ was maintained with use of optimized intermittent lighting and was the probable source for the improvements observed. It is suggested that providing regular short dark moments temporarily shuts down formation of $\mathrm{Ru}(\mathrm{bpy})_{3}{ }^{3+}$. This allowed water oxidation to progress more fully on the metal oxide and also periodic reduction or elimination of self-degradation of excess oxidized light sensitizer. Increased relative dark periods were found to be detrimental. Conversely, infrequent light interruption gave little difference compared to constant illumination. Thus, a balance of dark periods whilst also maintaining the ongoing photoreaction with sufficient illumination was necessary. Changes in reaction $\mathrm{pH}$ are complex as proton generation from the water oxidation was opposed by generation of

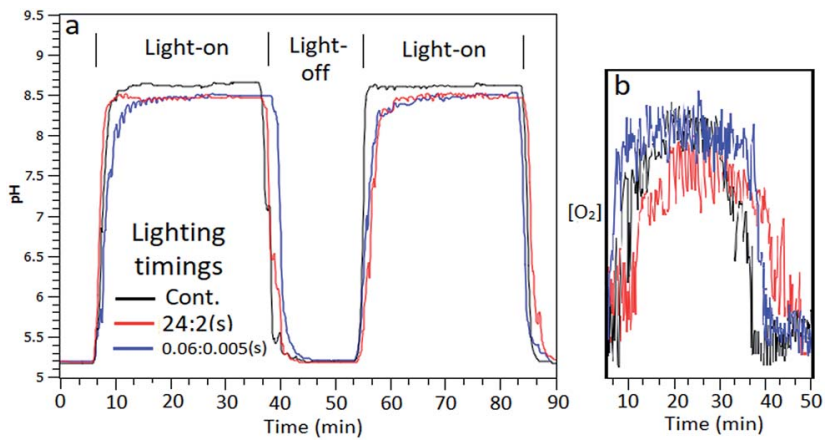

Fig. 7 Flow system showing (a) change in $\mathrm{pH}$ after light on/off and time taken to reach steady state for systems with tubing illuminated continuously, for $24: 2$ (s: s) and $0.06: 0.005$ (s: s) on : off. $10 \mathrm{~min}$ light off periods were also used to show time taken to reach steadystate; (b) measured increase in gaseous $\mathrm{O}_{2}$ concentration over base level, the low reaction mixture volume was reflected in variability of readings, however a trend of increased $\mathrm{O}_{2}$ release with fast intermittent timing was indicated.

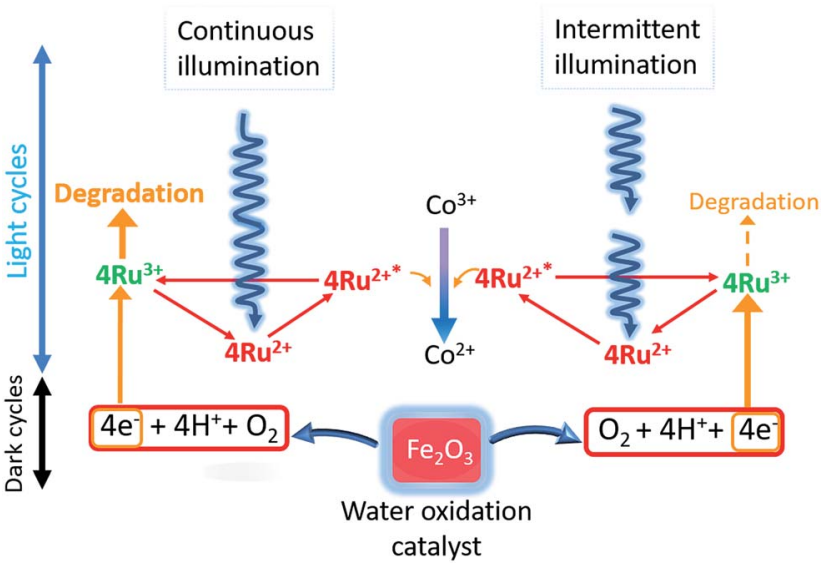

Scheme 2 Representation of visible light promoted photocatalytic water oxidation. In comparison to continuous illumination, intermittent lighting allowed the rate limiting water oxidation at the metal oxide surface to keep pace better with the light promoted sensitizer redox cycle. We suggest lessened excess oxidized sensitizer selfdecomposition (into hydroxylated bipyridine derivatives) and overall improved synchronization of the cyclic reactions with interrupted lighting promoted reaction efficiency.

ammonia from decomposed electron acceptor. With $\mathrm{CaMn}_{3} \mathrm{O}_{6}$ catalyst, diversion of generated protons to attack on the calcium component appeared significant as the best performing system resulted in highest final $\mathrm{pH}$. For the other catalysts proton generation counteracted ammonia formation with final $\mathrm{pH}$ remaining below 7 . Benefits of using dark periods are inversely proportional to catalyst efficiency, since less excess oxidized sensitizer will be present with more active catalysts. Scheme 2 shows a proposed schematic representation of the photocatalytic water oxidation system under continuous and tuned intermittent lighting. Under continuous illumination excess oxidized sensitizer can accumulate and undergo degradation, with intermittent illumination flow of electrons from the metal oxide matches to oxidized sensitizer levels more effectively lessening the sensitizer degradation pathway.

The comparison of batch versus flow system firstly showed that the limitation of reaction duration can be largely eliminated by the continuous flow assembly. Secondly the results were in accordance with batch system since the fast $0.06: 0.005$ ( $\mathrm{s}: \mathrm{s})$ on : off was equivalent to gaseous $\mathrm{O}_{2}$ output as continuous lighting (Fig. 7b). Steady state $\mathrm{pH}$ was lessened compared to continuous light which can be ascribed to increased proton output counteracting electron acceptor ammonia generation, as was found with $\mathrm{Co}_{3} \mathrm{O}_{4}$ catalysed batch systems.

\section{Conclusions}

Simple non-rare earth catalysts were prepared with a short calcination synthesis using biopolymer templates. It is notable that the templating synthesis resulted in some enhancement of the hematite (110) relative to the (104) plane (compared to normal bulk hematite), (110) enhancement is associated with improved water splitting ability. ${ }^{24}$ 
Under normal photocatalysis conditions abundant metal oxides are moderately active in comparison to toxic and/or costly rare earths $\left(\right.$ e.g. $\left.\mathrm{IrO}_{2}\right) .{ }^{17}$ Previously, photo-water oxidations using light at a range of intensities (fixed for the duration of each reaction) resulted in lower TON, $\mathrm{O}_{2}$ yield and increased lag time. ${ }^{10}$ In this work, photoreactions using the hematite catalyst employed intermittent light at fixed on : off ratios and activity of the catalysts markedly increased at optimum timings. Thus, differences in efficiency cannot simply be ascribed to an overall lowered light intensity reducing sensitizer decomposition. This is because the differing ratios gave altered $\mathrm{O}_{2}$ yields and $\mathrm{pH}$ effects, even though overall photon flux was identical.

A dark period that matches reagent to diffusion rates and levels of oxidized sensitizer can be expected to be optimal. Interestingly, this technique can particularly be of benefit with low cost earth abundant catalysts more as these tend to be less active compared to more efficient but costlier rare earth based catalysts.

For use with natural sunlight, readily available fast switching liquid crystal shutter panel systems can control optimized intermittent light delivery onto a reaction vessel or continuous flow tube.

$\left[\mathrm{Ru}(\mathrm{bpy})_{3}\right]^{2+}$ is also increasingly being employed as photoredox agent in for example organic catalysis, ${ }^{25}$ photopharmacology, ${ }^{26}$ natural product synthesis, ${ }^{27}$ amine oxidations $^{28}$ and biochemical couplings such as C-S click reactions. ${ }^{29}$ Therefore, the effects of intermittent light source illumination has implications for these wider uses in terms of reaction pathway and improved yields.

Hydrogen generation is readily achieved using well established polymer electrolyte membrane (PEM) proton separation plus catalysed reduction technologies. ${ }^{30,31}$ A continuous flow system, as demonstrated here, is particularly suitable for larger scale $\mathrm{H}_{2}$ generation.

Our further studies on solar fuel production will investigate if intermittent light intensity effects can enhance redox reactions including water oxidations using non-rare earth $\mathrm{Zn}$ porphyrin or robust Pt-porphyrin light sensitizers. ${ }^{32,33}$ A particular future aim is use of modified $\left[\mathrm{Fe}(\mathrm{bpy})_{3}\right]^{2+}$ sensitizer structures with increased excited state lifetimes. ${ }^{34}$ Alternatively, quinone derivatives as electron harvesters can replace irreversible electron acceptors..$^{35,36}$ The overall long term aim is the development of effective low toxicity, earth abundant photocatalytic systems.

\section{Conflicts of interest}

There are no conflicts to declare.

\section{Acknowledgements}

We thank Y. Y. Kim and A. Kulak, University of Leeds for assistance with BET and powder XRD measurement. DW and MTW acknowledge funding from a UoB Faculty of Science departmental grant. KR acknowledges the EPSRC Grand Challenge Network Direct Assembly Network (PP14 11 03) for funding. We would like to thank Vapourtec UK for their kind donation of the SF-10 pump for use in the flow experiments.

\section{References}

1 S. Styring, Faraday Discuss., 2012, 155, 357-376.

2 Y. Tachibana, L. Vayssieres and J. R. Durrant, Nat. Photonics, 2012, 6, 511-518.

3 K. J. Young, L. A. Martini, R. L. Milot, R. C. S. Iii, V. S. Batista, C. A. Schmuttenmaer, R. H. Crabtree and G. W. Brudvig, Coord. Chem. Rev., 2012, 256, 2503-2520.

4 J. Van Houten and R. J. Watts, J. Am. Chem. Soc., 1976, 98, 4853-4858.

5 L. Duan, Y. Xu, P. Zhang, M. Wang and L. Sun, Inorg. Chem., 2010, 49, 209-215.

6 A. Harriman, G. Porter and P. Walters, J. Chem. Soc., Faraday Trans. 2, 1981, 77, 2373-2383.

7 B. Limburg, E. Bouwman and S. Bonnet, ACS Catal., 2016, 6, 5273-5284.

8 C. Herrero, A. Quaranta, W. Leibl, A. W. Rutherford and A. Aukauloo, Energy Environ. Sci., 2011, 4, 2353-2365.

9 M. Morikawa, Y. Ogura, N. Ahmed, S. Kawamura, G. Mikami, S. Okamoto and Y. Izumi, Catal. Sci. Technol., 2014, 4, 16441651.

10 D. Walsh, N. M. Sanchez-Ballester, V. P. Ting, S. R. Hall, L. R. Terry and M. T. Weller, Catal. Sci. Technol., 2015, 5, 4760-4764.

11 D. Walsh, P. Patureau, J. Walton, J. Potticary, S. R. Hall and M. T. Weller, RSC Adv., 2016, 6, 97363-97366.

12 F. Jiao and H. Frei, Angew. Chem., Int. Ed., 2009, 48, 18411844.

13 Y. Y. Kim, D. Williams, F. C. Meldrum and D. Walsh, Small, 2013, 9, 61-66.

14 J. Hadermann, A. M. Abakumov, L. J. Gillie, C. Martin and M. Hervieu, Chem. Mater., 2006, 18, 5530-5536.

15 D. Walsh, N. M. Sanchez-Ballester, K. Ariga, A. Tanaka and M. Weller, Green Chem., 2015, 17, 982-990.

16 C. Creutz and N. Sutin, Proc. Natl. Acad. Sci. U. S. A., 1975, 72, 2858-2862.

17 M. Hara, C. C. Waraksa, J. T. Lean, B. A. Lewis and T. E. Mallouk, J. Phys. Chem. A, 2000, 104, 5275-5280.

18 B. Loll, J. Kern, W. Saenger, A. Zouni and J. Biesiadka, Nature, 2005, 438, 1040-1044.

19 Y. Umena, K. Kawakami, J.-R. Shen and N. Kamiya, Nature, 2011, 473, 55-60.

20 Y.-Y. Kim, D. Williams, F. C. Meldrum and D. Walsh, Small, 2013, 9, 61-66.

21 A. Vaidyalingam and P. K. Dutta, Anal. Chem., 2000, 72, 5219-5224.

22 S. Chang, X. Yang, Y. Sang and H. Liu, Chem. - Asian J., 2016, 11, 2352-2371.

23 R. Zhou, S.-Z. Kang, X. Li, L. Wang, L. Qin and J. Mu, RSC Adv., 2015, 5, 6954-6961.

24 S. Kment, P. Schmuki, Z. Hubicka, L. Machala, R. Kirchgeorg, N. Liu, L. Wang, K. Lee, J. Olejnicek, M. Cada, I. Gregora and R. Zboril, ACS Nano, 2015, 9, 7113-7123. 
25 D. A. Nicewicz and D. W. C. MacMillan, Science, 2008, 322, 77-80.

26 V. H. S. van Rixel, B. Siewert, S. L. Hopkins, S. H. C. Askes, A. Busemann, M. A. Siegler and S. Bonnet, Chem. Sci., 2016, 7, 4922-4929.

27 T. P. Nicholls, D. Leonori and A. C. Bissember, Nat. Prod. Rep., 2016, 33, 1248-1254.

28 M. Rueping, C. Vila, A. Szadkowska, R. M. Koenigs and J. Fronert, ACS Catal., 2012, 2, 2810-2815.

29 S. S. Zalesskiy, N. S. Shlapakov and V. P. Ananikov, Chem. Sci., 2016, 7, 6740-6745.

30 Y. Wang, K. S. Chen, J. Mishler, S. C. Cho and X. C. Adroher, Appl. Energy, 2011, 88, 981-1007.
31 J. Tymoczko, F. Calle-Vallejo, W. Schuhmann and A. S. Bandarenka, Nat. Commun., 2016, 7, 10990.

32 D. G. Nocera, Acc. Chem. Res., 2012, 45, 767-776.

33 H.-C. Chen, D. G. H. Hetterscheid, R. M. Williams, J. I. van der Vlugt, J. N. H. Reek and A. M. Brouwer, Energy Environ. Sci., 2015, 8, 975-982.

34 L. A. Fredin, M. Pápai, E. Rozsályi, G. Vankó, K. Wärnmark, V. Sundström and P. Persson, J. Phys. Chem. Lett., 2014, 5, 2066-2071.

35 D. Walsh, N. M. Sanchez-Ballester, V. P. Ting, K. Ariga and M. T. Weller, Catal. Sci. Technol., 2016, 6, 3718-3722.

36 E. J. Son, J. H. Kim, K. Kim and C. B. Park, J. Mater. Chem. A, 2016, 4, 11179-11202. 